Originalni naučni rad

Dr Marko S. Knežević, docent

Univerzitet u Novom Sadu

Pravni fakultet u Novom Sadu

mknezevic@pf.uns.ac.rs

Dr Radenka M. Cvetić, redovni profesor

Univerzitet u Novom Sadu

Pravni fakultet u Novom Sadu

rcvetic@pf.uns.ac.rs

\title{
PRIRODA ROKOVA ZA SUDSKU DRŽAVINSKU ZAŠTITU (ČL. 77 ZOSPO)
}

Sažetak: Sudska zaštita državine - tzv. posesorna zaštita u posebnom parničnom postupku - je oročena. Vladajuće shvatanje u tom smislu govori o rokovima za tzv. državinske tužbe, koji su materijalnopravnog karaktera. Ujedno, međutim, zakonodavac odavno tretira ove rokove kao procesnopravne, s obzirom da neblagovremenost tužbe predstavlja razlog za njen odbačaj. U radu se ispituje priroda ovih rokova polazeći od sasvim drugačijeg poimanja subjektivnih prava od onog koji je još uvek većinski. Smetanjem državine nastaju državinski zahtevi kao posebna kategorija subjektivnih prava, a ne nekakvo pravo na tužbu. Rokovi iz čl. 77 ZOSPO su ništa drugo do rokovi trajanja zahteva, prekluzivnog i materijalnopravnog karaktera.

Ključne reči: sudska državinska zaštita; rok za tužbu; subjektivno pravo; zahtev.

\section{SUDSKA DRŽAVINSKA (POSESORNA) ZAŠTITA}

Kompleksnost državine kao ustanove na najbolji način opisuju Vodinelićeve početne rečenice iz njegove skorašnje monumentalne studije: „malo toga je nesporno o državini u pogledu osnovnih pitanja. Ali je bar nesporno da je sporno". ${ }^{1}$ Poznato je da do danas vlada spor o prirodi državine (faktičko stanje koje se štiti

\footnotetext{
${ }^{1}$ Vladimir Vodinelić, Državina, Beograd 2015, 16.
} 
ili subjektivno pravo), ${ }^{2}$ kao i spor o razlogu zaštite državine, odnosno o tome šta se štiti u tzv. posesornom sporu. ${ }^{3}$ Kako god da se zauzme stav o navedenim pitanjima, pozitivnopravno gledano, jasno je da držalac, bez obzira na pravo na državinu, uživa zaštitu od samovlasnog i protivpravnog smetanja državine, u čemu se vidi zaštitna funkcija državine kao njeno najznačajnije pravno dejstvo. ${ }^{4} \mathrm{Put}$ zaštite je dvojak: samopomoć (čl. 76 ZOSPO), ili sudska zaštita (čl. 77 i sled. ZOSPO), koja se naziva i sudskom državinskom (posesornom) zaštitom.

Skupni izraz za sve radnje kojima se vrši povreda državine je smetanje drŽavine (čl. 75 ZOSPO; upor. i čl. 448 i sled. ZPP). Tipološki, smetanje državine je već prema pozitivnom pravu dvojako. S jedne strane je oduzimanje državine, u smislu potpunog deposedovanja dotadašnjeg držaoca (gubitak državine), dok su svi ostali slučajevi uznemiravanje državine. U okviru potonjeg, analogno uznemiravanju svojine, ${ }^{5}$ izdvajaju se dalje vrste: delimično ograničenje državine zasnivanjem trajnog stanja (npr. istovar šuta na parcelu), povremeno ili trajno otežano korišćenje faktičke vlasti (prelazak preko parcele, imisije preko granice tolerancije). ${ }^{6,7}$

Za sudsku posesornu zaštitu je karakteristično da se govori da se ona ostvaruje tužbom (tzv. državinska tužba), s obzirom da se zaštita pruža u parničnom

${ }^{2}$ Preciznije subjektivno pravo na isključivanje drugih od uticaja na državinu, što zastupa V. Vodinelić, (2015), 38 i sled. Za iscrpno upućivanje na literaturu o prirodi državine vid. V. Vodinelić (2015), 15.

${ }^{3}$ Up. V. Vodinelić (2015), 104 i sled., naročito 135 i sled. gde postavlja tezu o zatečenoj pojavnoj slici prava i obaveza kao razloga državinske zaštite.

${ }^{4}$ Up. Harry Westermann, Sachenrecht, Karlsruhe 19604, § 21 br. 1; Helmut Koziol, Rudolf Welser, Grundriss des bürgerliches Rechts, Bd. I, Wien 200011, 241; Miroslav Lazić, „Pravna dejstva državine prema Srpskom građanskom zakoniku”, u: Zbornik radova Pravnog fakulteta u Nišu 'Sto pedeset godina od donošenja Srpskog građanskog zakonika (1844-1994)“, Niš 1995, 180; Slavica Krneta, „Posjed”, u: Enciklopedija imovinskog prava i prava udruženog rada, Beograd 1978, 1011.

${ }^{5}$ Korišćenje istih termina - uznemiravanje svojine (čl. 42 st. 1 ZOSPO) i uznemiravanje državine (čl. 75 ZOSPO) - te suštinska ista pravozaštitna funkcija (obezbeđivanje zaštite državine, na osnovu prava na državinu ili na osnovu same državine), dozvoljavaju da se tipologija smetanja državine, naročito uznemiravanja, izradi analogno uznemiravanju svojine. O toj povezanosti iz perspektive nemačkog prava, koje se na redakcijskom planu za ovaj kontekst ne razlikuje od ZOSPO, upor. Hans Prütting, u: H. Prütting, G. Wegen, G. Weinreich (Hrsg.), BGB Kommentar, Köln $2009^{4}, \S 859$ br. $3, \S 862$ br. 1 .

${ }^{6} \mathrm{Da}$ su nedopuštene imisije takođe smetanje državine danas up. Obren Stanković, u: O. Stanković, M. Orlić, Stvarno pravo, Beograd 19959, 48 (br. 163); Danica Popov, „Tužba zbog smetanja državine izazvanih imisijama", Zbornik Pravnog fakulteta u Novom Sadu 2015, 1498. Za nemačko pravo reprezentativno BGH (Savezni sud), 14.10.1994, V ZR 76/93, Neue Juristische Wochenschrift (NJW) 1995, 132. Za druge pravne sisteme vid. sa daljim upućivanjima V. Vodinelić (2015), 83/84.

${ }^{7} \mathrm{O}$ brojnim dilemama u pogledu pojedinosti pojma „smetanja” V. Vodinelić (2015), 76 i sled. 
postupku. Tako su spram tipologije smetanja konstruisane različite „državinske tužbe": tužba zbog oduzimanja državine, koja je uperena na predaju oduzete stvari; tužba zbog uznemiravanja državine, koja je prema vrsti uznemiravanja usmerena ili na uspostavljanje ranijeg državinskog stanja (u gornjem primeru uznemiravanja istovarom šuta, uperena je na njegovo uklanjanje), ili na zabranu, propuštanje radnji koje predstavljaju uznemiravanje državine.

Osnovne odlika sudske posesorne zaštite u našem pravu je njena provizornost, te hitnost i sumarnost postupka. Postojeći model koji odslikava ove odlike je nesumnjivo austrijskog porekla.

Provizornost podrazumeva da pravnosnažnost odluke u ovom sporu ne utiče na kasniji tzv. petitorni spor - spor u kojem će se raspravljati o pravu na državinu; odluka iz posesornog postupka je u tom smislu uvek privremena, provizorna. ${ }^{8}$ Smatra se da je izraz te zamisli koncept odlučivanja u posesornom sporu: meritorna odluka o tužbi nije presuda, već rešenje, ${ }^{9}$ što je preuzeto iz austrijskog prava, gde je tako nešto istorijski uslovljeno. ${ }^{10}$

Težnja za brzim okončanjem postupka se ogleda ne samo u tome da su ovi sporovi hitni (čl. 449 st. 1 ZPP), što bi značilo da zakazivanje ročišta u njima ima prioritet u odnosu na druge, kao i u pogledu odlučivanja o pravnim lekovima, već su i sama pravila postupka u smislu redukcije opštih pravila izraz ideje o brzom okončanju: tužba se ne dostavlja na odgovor tuženom, već se odmah zakazuje ročište za glavnu raspravu (čl. 449 st. 2 ZPP), a rok za žalbu je osam dana (čl. 452 st. 2 ZPP).

Sumarnost je vidljiva iz predmeta raspravljanja, tj. isključivanja raspravljanja o pravu na državinu, pravnom osnovu i savesnosti državine, te u nemogućnosti kumuliranog utuženja odštetnih zahteva (čl. 450 st. 1 ZPP). ${ }^{11}$

\section{OROČENOST SUDSKE DRŽAVINSKE ZAŠTITE}

Sudska državinska zaštita je oročena. Prema ZOSPO, ona se može tražiti samo u određenim, kratkim rokovima. Otuda se govori o rokovima za državinske

${ }^{8}$ Upor. Karl-Heinz Schwab, Sachenrecht, München 1989²2, 40; Robert Fucik, u: W. Rechberger, T. Klicka (Hrsg.), Kommentar zur ZPO, Wien 20195, 1686 (§ 459 br. 1); Aleksandar Jakšić, Građansko procesno pravo, Beograd 20179, 725 (br. 3824). Štaviše, u austrijskoj doktrini se govori o „bliskosti sa privremenim merama”; tako Andreas Konecny, u: H. Fasching, A. Konecny (Hrsg.), Kommentar zu Zivilprozessgesetzen, Bd. III/1, Wien 2017², 2 (Einl. br. 4).

${ }^{9}$ O. Stanković, u: O. Stanković, M. Orlić, 54 (br. 185).

${ }^{10}$ Oskar Ballon, Einführung in das österreichischen Zivilprozessrecht, Graz 2009², br. 497.

${ }^{11}$ O shvatanjima za slučaj da tuženi podnese petitornu protivtužbu up. Borivoje Poznić, Komentar Zakona o parničnom postupku, prema tekstu zakona iz 1976. godine sa docnijim izmenama i dopunama, Beograd 2009, 1046. 
tužbe. Sadašnji koncept koji postoji od 1956. godine podrazumeva dva roka - subjektivni i objektivni. Subjektivni iznosi 30 dana i računa se od saznanja za smetanje državine i učinioca; objektivni iznosi godinu dana i računa se od učinjenog smetanja (čl. 77 ZOSPO). ${ }^{12}$ Subjektivni rok teče u okviru objektivnog, i istekom potonjeg istekao je i subjektivni, iako možda nije isteklo 30 dana od saznanje za smetanje i učinioca. Uz to, u oročenost sudske državinske zaštite svakako spada i oročavanje zahteva za izvršenje: on postoji samo 30 dana od izvršnosti državinskog rešenja (čl. 453 ZPP).

Smisao oročenosti sudske zaštite državine se uglavnom obrađuje spram konkretnog vremena, dakle u smislu kratkoće rokova. U tom smislu, kratkoća rokova je posledica provizornosti državinske zaštite: ukoliko se priznaje zaštita od samovlasnog smetanja državine jednom licu nezavisno od njegovog prava na državinu, a ona je provizorna, obzirom da rezultat postupka (pravnosnažna odluka) ne utiče na kasniji tzv. petitorni spor, onda je kratkoća rokova smislena; ona je izraz koncepta hitnosti. ${ }^{13}$ Time je i prećutno dat razlog za postojanje bilo kakvog roka: ako je zaštita provizorna i hitna, onda mora da bude oročena uopšte. ${ }^{14}$ To je stabilizirajuća funkcija u smislu da protekom određenog vremena po učinjenom smetanju stanje državine ne treba da se putem državinske zaštite iznova menja, već da se stvar raspravi samo u petitornom sporu..$^{15}$

Na procesnom planu, u pogledu razrade koncepta oročenosti tužbe, prisutno je postojano rešenje: neblagovremena državinska tužba se odbacuje. Tako nešto je bilo predviđeno još u predratnom pravu (§ 548 reč. $3 \mathrm{Grpp}$ ), i predstavljalo je odstupanje od austrijskog uzora. ${ }^{16}$ Donošenjem prvog posleratnog ZPP 1956. godine taj koncept je potvrđen, ali na opštem planu: nije bilo predviđeno da se neblagovremena državinska tužba odbacuje, već uopšte, svaka neblagovremena tužba treba da se odbaci (čl. 271 st. 1 ZPP 1956). Time je jasno bilo da je neblagovremenost tužbe postala procesna smetnja, kao pojavni oblik procesne pretpostavke. Takav koncept je preuziman u svim sledećim zakonima, zaključno sa danas važećim ZPP (čl. 294 st. 1 t. 2). U njemu je, kao i u njegovom prethodniku, te noveliranom ZPP iz 1976, dodatno potvrđen koncept: meritorno odlučivanje o

12 Do Zakona o parničnom postupku iz 1956. godine, postojao je samo subjektivni rok od 30 dana od saznanja za smetanje i učinioca. Radilo se o pravilu iz § 548 reč. 2 Građanskog parničnog postupka (Grpp) iz 1929, koji je bio, uz određene, ne tako brojne izmene, prevod austrijskog Grpp (aGrpp). Ovaj koncept oročenosti je još uvek važeći u Austriji (§ 454 aGrpp).

${ }^{13}$ Up. V. Vodinelić, 91/92.

${ }^{14}$ U tom smislu Siniša Triva, Velimir Belajec, Mihajlo Dika, Građansko parnično procesno pravo, Zagreb $1986^{6}, 662$.

${ }^{15} \mathrm{Up}$. H. Westermann, § 21 br. 3.

${ }^{16} \mathrm{U}$ austrijskom Grpp nije sadržana odredba po kojoj neblagovremenu državinsku tužbu sud odbacuje. O shvatanju ovog problema u austrijskom pravu vid. dole fn. 28. 
neblagovremenoj tužbi je apsolutno bitna povreda postupka, koja vodi ukidanju odluke i odbacivanju tužbe (čl. 374 st. 2 t. 3, 391 st. 3 ZPP).

\section{SHVATANJA O PRIRODI ROKOVA ZA SUDSKU DRŽAVINSKU ZAŠTITU; POSTAVLJANJE PROBLEMA}

Pitanje koje se postavlja u pogledu rokova, pored onog koji je naročito praktične prirode (početak rokova kod ponovljenih i trajnih smetanja) ${ }^{17}$ jeste i ono o pravnoj prirodi, i to u dvostrukom smislu. Prvo, da li je to procesnopravni ili materijalnopravni rok, a drugo, ako je materijalnopravni, onda da li je prekluzivni ili zastarni, s obzirom da procesno pravo ne poznaje zastarelost.

Dilema da li su rokovi procesnopravni ili materijalnopravni danas je utihnula, s obzirom da gotovo i da nema onih koji bi negirali materijalnopravnu prirodu, i to u smislu prekluzivnosti rokova. ${ }^{18}$ Ipak, argumentacija za materijalnopravnu prirodu se redovno ne daje. Tamo gde je to slučaj, vidljiva su dva pravca. Prvi je suštinski, jer polazi od predmeta oročenosti. Tako, pošto je rok za tužbu zapravo rok postojanja samog prava za koje se traži zaštita u parnici, onda je on materijalnopravni. ${ }^{19}$ Drugi je formalni, jer vezuje prirodu roka za mesto gde je on propisan, a tvrdi se da je to jedan od pouzdanijih kriterijuma. ${ }^{20}$ Ovaj drugi pravac nije zapravo nov, već je postojao i ranije, sa drugačijim rezultatom. Naime, polazeći od okolnost da su rokovi ranije bili sadržani u procesnim propisima, zastupao se stav da su oni procesne prirode. ${ }^{21}$

${ }^{17}$ O tome više O. Stanković, u: O. Stanković, M. Orlić, 49 (br. 167-168); B. Poznić, 1045; A. Jakšić, 724 (br. 3818-3819); Borivoje Poznić, Vesna Rakić-Vodinelić, Građansko procesno pravo, Beograd 2015 17, 532; GO VSS od 19.10.1978, Zbornik sudkse prakse 35 (1980), 50. Za nemačko pravo sa daljim upućivanjima na teoriju vid. $B G H, 14.10 .1994$, V ZR 76/93, $N J W 1995,132$. Za austrijsko pravo sa daljim upućivanjima na sudsku praksu vid. R. Fucik, u: W. Rechberger, T. Klicka (Hrsg.), 1683 (§ 454 br. 6).

${ }^{18}$ B. Poznić, 1044; S. Triva, V. Belajec, M. Dika, 662; A. Jakšić, 724 (br. 3817); B. Poznić. V. Rakić-Vodinelić, 532; Života Janković, u: M. Janković et alt., Komentar Zakona o parničnom postupku, Beograd 19903, 458; Gordana Stanković, Građansko procesno pravo, Niš 20077, 530; Ranko Keča, u: Borivoj Starović, Ranko Keča, Građansko procesno pravo, Novi Sad 20043, 450; Radmila Kovačević Kuštrimović, Miroslav Lazić, Stvarno pravo, Niš 2006, 70; Suprotno samo Ilija Babić, Građansko pravo, Knjiga 1, Uvod u građansko pravo, Beograd 2011, 243 (br. 991), koji iako se ne izjašnjava izričito o prirodi roka, tvrdi da je ovaj prekluzivni rok propisan ,u procesnom pravu“, a isto tvrdi i za „rok za tužbu za poništenje rušljivog ugovora“. Samo u rezultatu isto Danica Popov, Građansko pravo, Novi Sad 20127, 315: „procesnopravna priroda”.

${ }^{19}$ B. Poznić, 694.

${ }^{20}$ R. Kovačević Kuštrimović, M. Lazić (2006), 70 fn. 44.

${ }^{21}$ Srećko Zuglia, Ante Verona, Zakonik o sudskom postupku u građanskim parnicama (Građanski parnični postupak) (s.a.), 656/657; Dragoljub Aranđelović, Građansko procesno pravo Kraljevine Jugoslavije II, Beograd 1933, 261 fn. 93. 
Zastupnici teze o materijalnopravnoj prirodi rokova, većinom ipak ne problematizuju pozitivnopravno stanje u pogledu svrstavanja blagovremenosti tužbe u procesne pretpostavke. To čini samo onaj deo koji se bavi prevashodno procesnim pravom. Polazeći od rečene prirode roka, jedni kritikuju zakonsko rešenje, s obzirom da bi bilo teorijski ispravno da se tužba odbija, a ne odbacuje. ${ }^{22}$ Drugi ga brane, smatrajući da se radi zapravo o pojavnom obliku apsolutne nenadležnosti suda, ${ }^{23}$ odnosno o nedostatku tuživosti. ${ }^{24}$

Izložene dileme su skicirale probleme rada. Okolnost što danas nema spora o prirodi rokova iz čl. 77 ZOSPO u smislu da li je materijalnopravne ili procesnopravne prirode ne znači da ne postoji potreba da se ispita valjanost vladajućeg shvatanja. Čini se da problem nije u samom rezultatu, već u argumentaciji, odnosno ishodištu. Ne postavlja se dublje dogmatičko pitanje, makar ne sasvim izričito i svesno. Ono glasi: na šta se zaista odnosi rok, odnosno koja je konkretna posledica prekluzije - šta se gubi protekom rokova iz čl. 77 ZOSPO? Čini se da je to posledica, pre svega, već evidentiranog deficita bavljenja temom subjektivnih prava u ukupnom jugoslovenskom i postjugoslovenskom prostoru. ${ }^{25} \mathrm{Jer}$, postavljena pitanja su neodovojivi deo učenja o subjektivnim pravima. Pri tome, ona nemaju veze sa vekovnim sporom o prirodi državine, već sa pojmom subjektivnog prava uopšte.

\section{PREKLUZIVNOST ROKOVA}

Traženje sudske zaštite, kako je to određeno u čl. 77 ZOSPO, nedvosmisleno ukazuje da se radi o roku za podnošenje tužbe. Jer, upravo se propisuje rok za traženje sudske zaštite, a ona se traži tužbom u parničnom postupku. ${ }^{26} \mathrm{~S}$ obzirom na čl. 370 ZOO, po kojem se na rokove predviđene za ponodšenje tužbe pravila o

22 S. Triva, V. Belajec, M. Dika, 663; B. Poznić, 694.

${ }^{23}$ Mihalo Dika, Građansko parnično pravo, Parnične radnje, V. knjiga, Zagreb 2008, 66 fn. 87 .

${ }^{24}$ A. Jakšić, 422 (br. 2094).

${ }^{25}$ Nikola Gavella, „O odnosu materijalnog i procesnog građanskog prava u parnicama”, u: A. Uzelac, J. Garašić, A. Maganić (ur.), Djelotvorna pravna zaštita u pravčnom postupku, Liber amicorum Mihajlo Dika, Zagreb 2013, 189 fn. 5.

${ }^{26} \mathrm{Da}$ je propisan rok za tužbu, a da se ne koriste te reči, pokazuje primer prava preobražajne tužbe za slučaj rušljivosti zaveštanja (čl. 170 ZN); upor. samo Dejan Đurđević, Institucije naslednog prava, Beograd 20157, br. 338. O pravima preobražajne tužbe kao subjektivnim pravima Dieter Medicus, Allgemeiner Teil des BGB, Heidelberg 2002 ${ }^{8}, 40-41$ (br. 83 i dalje); o sporu da li se radi o materijalnopravnom ili procesnopravnom (time i javnopravnom) subjektivnom pravu vid. sa daljim upućivanjima: Leo Rosenberg, Karl-Heinz Schwab, Peter Gottwald, Zivilprozessrecht, München 2010 17 , 501 (§ 91 br. 2 i dalje); Herbert Roth, u: Stein/Jonas, Kommentar zur Zivilprozessordung, Bd. IV, Tübingen 2008 22 , ispred $\S 253$ br. 103; Dorothea Assmann, u: Wieczorek/Schütze, 
zastarelosti ne primenjuju, jasno je da se ovde ne radi o roku zastarelosti. Time svakako nije rešeno osnovno pitanje: da li se radi o materijalnopravnom ili procesnopravnom roku.

\section{MATERIJALNOPRAVNI KARAKTER ROKOVA}

\subsection{Nepodobnost formalnog kriterijuma (mesto uređenja)}

Formalni kriterijum za određivanje pravne prirode rokova za sudsku državinsku zaštitu, u smislu mesta uređenja (procesni ili materijalnopravni zakon), ne predstavlja podoban argument. Suprotno od onoga što se tvrdi, mesto norme ne pruža pouzdan oslonac za stav o njenoj prirodi, a pitanje je da li pruža bilo kakav oslonac. Stav zakonodavca na kom mestu će da uredi jedno pitanje nikada nema značaj ni indicije za određivanje pravne prirode. Upravo zato je razumljivo što je u domaćoj teoriji do 1980. godine, kada su rokovi za sudsku državinsku zaštitu bili sadržani u procesnim zakonima, većinski stav bio da se radi materijalnopravnom roku, ${ }^{27}$ a tako je još uvek u austrijskom pravu. ${ }^{28}$

Kvalifikacija pravne prirode mora da se zasniva na suštinskim razlozima. Da li je jedna norma materijalnopravne ili procesnopravne prirode, zavisi od toga šta ona uređuje. U kontekstu rokova: na šta se oni odnose, koja su njihova pravna dejstva. Prema tome, prethodno pitanje je: šta zaista nastaje smetanjem državine?

\subsection{Posledica smetanja državine: šta zaista nastaje?}

Smetanjem državine ne nastaje nikavo pravo na tužbu, ili tužba u materijalnom smislu, što bi bila zapravo posledica učenja još uvek većinske doktrine kod

Zivilprozessordnung und Nebengesetze, Bd. 4, Berlin $2013^{4}$, ispred $\S 253$ br. 14; Andreas Geroldinger, u: H. Fasching, A. Konecny (Hrsg.), 65-66 (§ 226 br. 58 i dalje).

${ }^{27}$ Za predratno pravo Srećko Culja, Građansko procesno pravo Kraljevine Jugoslavije, sv. 1, Beograd 1936, 658; Franjo Goršić, Komentar Građanskog parničnog postupka II, Beograd 1932, 306; za posleratno pravo Borivoje Poznić, Građansko procesno pravo, Beograd 1962, 338; Borivoje Poznić, u: B. Poznić, M. Vražalić, F. Bačić, Zakon o parničnom postupku, sa komentarom, Beograd 1957, 370; Siniša Triva, Građansko procesno pravo I, Zagreb 1972², 649; Milka Janković et alt., Komentar Zakona o parničnom postupku, Beograd 1977, 519.

${ }^{28}$ Već 1902. godine OGH (Vrhovni sud), AmtSlgNF IV, br. 577 zauzima stav da je rok materijalno pravni, jer se ne odnosi prosto na tužbu kao parničnu radnju, već na materijalno pravo koje se tužbom ostvaruje. Danas to je vladajuće shvatanje teorije i sudske prakse, vid. sa daljim upućivanjima R. Fucik, u: W. Rechberger, T. Klicka (Hrsg.), 1682 (§ 454 br. 5); Walter Rechberger, Daphne-Ariane Simotta, Zivilprozessrecht, Wien 20097, 502 (br. 952); Hans Fasching, Lehrbuch des österreichischen Zivilprozeßrechts, Wien $1990^{2}$, br. 1651. Suprotno samo Georg Kodek, u: A. Fenyves, F. Kerschner, A. Vonklich (Hrsg.), ABGB Klang, Bd. 6, Wien 2011³, 416 i dalje (§ 339 br. 240 i dalje). 
nas. Po tom učenju, povredom subjektivnog prava nastaje tužba u materijalnom smislu, za koju je još koristi termin „zahtev“ kao sinonim, a koja nije nikakvo posebno subjektivno pravo, već ukorenjeni element postojećeg subjektivnog prava koji se aktivira u slučaju povrede. ${ }^{29}$ Tužba u materijalnom smislu je zapravo svedena na mogućnost da se povređeno subjektivno pravo ostvari sudskim putem, ${ }^{30}$ pa upravo na taj način ovo učenje objašnjava zastrelost i prekluziju: kada dođe do zastarelosti ne gubi se samo subjektivno pravo, već tužba u materijalnom smislu; ${ }^{31}$ kod prekluzije pravo prestaje. ${ }^{32} \mathrm{Za}$ razliku od tužbe $\mathrm{u}$ materijalnom smislu, koja je suština, postoji tužba u formalnom, a to je sam inicijalni podnesak u postupku - sam akt obraćanja sudu. ${ }^{33}$ Za slučaj smetanja državine, s obzirom da se zastupa teza da to nije subjektivno pravo, nastaje jedna takva tužba ili zahtev, ali on nije subjektivno pravo. ${ }^{34} \mathrm{U}$ pogledu ključnog pitanja - „Šta je to ako nije subjektivno pravo?" - ne daje se odgovor.

U ukupnosti ovo učenje nije ništa drugo do akcionopravno shvatanje subjektivnih prava i prava na tužbu, koje je gotovo identično shvatanju Savinjija. ${ }^{35,36}$ Ono je bilo prihvatljivo u njegovo vreme (sredina XIX veka) kada se procesna dogmatika još nije bila razvila, pa je sve bilo objašnjavano materijalnopravnim kategorijama. Onda ne čudi da je suština tužbe bila zapravo materijalnopravna kategorija, te da je bilo vladajuće učenje o materijalnopravnom predmetu spora - to je bila upravo tužba u materijalnom smislu. ${ }^{37}$

${ }^{29}$ Vid. Milijan Popović, Pojam subjektivnog prava, Novi Sad 1974, 245 i sled., 259 i sled.; Andrija Gams, Ljiljana Đurović, Uvod u građansko pravo 199417, 65 i sled., 239; Dušan Nikolić, Uvod u sistem građanskog prava, Novi Sad 2013"11, 223; I. Babić, 126-127 (br. 430-431); D. Popov (2012), 128/129; Radmila Kovačević Kuštrimović, Miroslav Lazić, Uvod u građansko pravo, Niš 2008, 161/162, 388.

${ }^{30}$ Poboljšana verzija ovog shvatanja je stav da je tužba u materijalnom smislu, odnosno zahtev, „mogućnost da se od nekog određenog lica traži ostvarenje nekog imovinskog efekta na osnovu subjektivnog prava prinudnim putem" (A. Gams. Lj. Đurović, 66).

${ }^{31}$ D. Nikolić, 245; A. Gams, Lj. Đurović, 65, 191; I. Babić, 237 (br. 964-965), 243 (br. 993).

32 Upor. I. Babić, 242-243 (br. 990 i dalje).

${ }^{33}$ A. Gams, Lj. Đurović, 239; I. Babić, 127 (br. 431): ,,materijalni deo tužbe je zahtev u materijalnom smislu, a procesna tužba je oblik u kome se ovaj zahtev ispoljava“.

${ }^{34}$ A. Gams, Lj. Đurović, 66.

${ }^{35}$ Upor. Carl Friedrich von Savigny, System des heutigen römischen Rechts, Bd. V, Berlin 1841, 4 i sled. Za sažetu rekonstrukciju Savinjijevih shvatanja i prihvaćenost njegove teorije u XIX veku Dieter Hesselberger, Die Lehre vom Streitgegenstand, Köln 1970, 72 i sled.; Horst Kaufmann, „Zur Geschichte des aktionenrechtlichen Denkens“, Juristenzeitung 1964, 488.

${ }^{36}$ Ocenu da je ovakvo shvatanje tadašnje jugoslovenske doktrine ništa drugo do nastavljanje Savinjijevog učenja daje već Slavica Krneta, „Evolucija pojma 'zahtjev' i njegov odnos prema subjektivnom pravu“, Godišnjak Pravnog fakulteta u Sarajevu XXIII (1975), 306/307; upor. i Marko Knežević, „Teret dokazivanja imisija kao pretpostavke negatornog zahteva“, Zbornik radova Pravnog fakulteta u Novom Sadu 4/2013, 356 i sled.

${ }^{37} \mathrm{O}$ ovom pravcu u razvoju teorije o pravu na tužbu iscrpno Mihajlo Dika, Pravo na tužbu, Zagreb 1987, 19 i sled. (civilistički monizam u XIX veku), 155 i sled. (civilistički monizam u domaćoj teoriji). 
Akcionopravno učenje je odavno napušteno u uporednom pravu, pre svega u Nemačkoj gde se zaokruženo artikulisalo. Savremeno shvatanje subjektivnih prava polazi od toga da - u kontekstu podele prema sadržini ovlašćenja - pored prava vlasti, prava ličnosti, preobražajnih prava, ${ }^{38}$ prava pripadanja, postoje i zahtevi, kao prava traženja. U njih spadaju kako potraživanja, tako i svi drugi zahtevi, koji nastaju ili kao posledica povrede nekog drugog subjektivnog prava (npr. reivindikacioni zahtev kao posledica porede prava svojine), ili kao posledica povrede nekog zaštićenog interesa ili pravne pozicije (tipičan primer je povreda pravila o poštenoj tržišnoj utakmici) ${ }^{39}$ U odnosu na njih, zahtev ima zaštitnu i pomoćnu funkciju (nem. Schutz- und Hilfsfunktion), ${ }^{40}$ ali se time ne negira da je subjektivno pravo. Zahtev podrazumeva ovlašćenje jednog lica da od drugog traži neko činjenje ili nečinjenje; on je materijalnopravne prirode, jer se odnosi na ponašanje učesnika pravnog prometa, odnosno ne tiče se postupka kao takvog. On nema nikakve veze sa pravom na tužbu, jer nije uperen prema državi - njegov adresat je lice na kome leži obaveza. To što je njega moguće ostvariti sudskim putem - što je „utuživ" - je samo njegova osobina kao prava, jer su prava u pravnoj državi redovno zaštićena. ${ }^{41}$ Kako to još Vindšajd (Windscheid) napominje, ako bismo govorili o pravu na sudsko sprovođenje (ostvarivanje), o jednom pravu tužbe, umesto samo o zahtevu, onda bismo imenovali posledicu umesto osnova; odnosno, utuživost je jedna strana zahteva, ali ne ona koja ga stvara. ${ }^{42} \mathrm{U}$ svakom slučaju, tuživost kao takvu ne treba nikako brkati sa pravom na tužbu, koje ima sasvim drugo značenje. Ukoliko se govori o vladajućem shvatanju, koje je i oprav-

${ }^{38}$ Još uvek je sporno u domaćoj nauci da se radi o subjektivnim pravima. Negativan stav: Obren Stanković, u: O. Stanković, V. Vodinelić, Uvod u građansko pravo, Beograd 20075, 107; A. Gams, Lj. Đurović, 67 i sled.; D. Nikolić, 221/222; I. Babić, 127-128 (br. 433-434). Pozitivan stav: Slavica Krneta, „Subjektivna prava“, u: Enciklopedija imovinskog prava i prava udruženog rada, Beograd 1977, br. 75; Vladimir Vodinelić, Građansko pravo, Uvod u građansko pravo i Opšti deo građanskog prava, Beograd 2012, 213 i dalje. Za austrijsko i nemačko pravo, gde je nesporno da su preobražajna prava subjektivna prava, umesto svih, sa daljim upućivanjima H. Koziol, R. Welser, 45; Reinhard Bork, Allgemeiner Teil des Bürgerliches Gesetzbuchs, Tübingen 2011³, 121 i dalje (br. 280 i dalje, naročito 285, 297).

${ }^{39}$ Upor. D. Medicus, 31 (br. 63), 35 i dalje (br. 73 i dalje); Hans Brox, Allgemeiner Teil des $B G B$, München 1999²3, 274 (br. 579), 280 i dalje (br. 591 i dalje); Helmut Köhler, BGB Allgemeiner Teil, München 200731, 231 (§ 17 br. 11), 237 i dalje (§ 18 br. 1 i dalje); H. Koziol, R. Welser, 44/45; za domaću teoriju upor. S. Krneta (1975), 308; V. Vodinelić (2012), 210 i sled.; M. Knežević (2013), 357 i sled.

${ }^{40}$ Ludwig Raiser, „Der Stand der Lehre vom subjektiven Recht im Deutschen Zivilrecht“, Juristenzeitung 1961, 466/467; V. Vodinelić (2012), 211 i sled.

${ }^{41}$ Up. S. Krneta (1977), br. 30; Marko Knežević, „Krug opozicionih razloga u prigovoru protiv rešenja o izvršenju na osnovu izvršne isprave“, Zbornik radova Pravnog fakulteta u Novom Sadu 4/2014, 343.

${ }^{42}$ Bernhard Windscheid, Lehrbuch des Pandektenrechts I, Düsseldorf $1875^{4}, 105$. 
dano spram pozitivnopravnog stanja, pravo na tužbu je pravo na pravosuđe ( $J u$ stizgewährungsanspruch), koje uopšte ne garantuje nikakav meritorni rezultat. Ono je osnovno ljudsko procesno pravo, danas jasno zagarantovano kroz pravo na pravično suđenje (čl. 32 st. 1 Ustava), ${ }^{43}$ ali i već kroz samo postojanje vladavine prava (čl. 1 Ustava), odnosno pravne države. ${ }^{44}$

Okolnost da se u domaćim zakonima još uvek koristi akcionopravna redakcija kada se predviđaju zahtevi ne utiče da dogmatiku građanskog prava. Dakle, to što nije predviđeno npr. da „,lasnik ima zahtev za predaju individualno određene stvari prema držaocu”, već da ,vlasnik može tužbom zahtevati od držaoca povraćaj individualno određene stvari” (čl. 37 st. 1 ZOSPO), ne znači da vlasnik nema zahtev kao subjektivno pravo. Radi se samo o reliktu akcionopravnog shvatanja, odnosno o njegovom uticaju na redaktore zakona. S druge strane, ima primera da redaktori nisu bili pod takvim uticajem. Tako, većina odredba ZOO zahvaljujući Konstantinovićevoj „Skici” ne spominje tužbe, već prosto zahteve i obaveze. Primera radi, u čl. 262 st. 1 ZOO predviđa se da je „poverilac u obaveznom odnosu ovlašćen da od dužnika zahteva ispunjenje obaveze", a ne, kako bi bila akcionopravna redakcija, da ,poverilac u obaveznom odnosu može tužbom da od dužnika zahteva ispunjenje obaveze“. Da je jedan sistem moguće shvatiti u skladu sa savremenim učenjem o zahtevima pokazuje sadašnja obrada austrijskog OGZ, koji je redigovan u akcionopravnom maniru, jer je on tada bio vladajući. Tamošnja literatura nema problem da npr. reivindikacioni zahtev označi kao subjektivno pravo u vidu zahteva, iako još uvek važi odredba koja govori o tužbi (§ $366){ }^{45}$

Imajući u vidu rečeno, smetanjem državine nastaje zahtev kao subjektivno pravo: pravo držaoca da traži od smetaoca, već prema tipologiji smetanja, da nešto uradi (da vrati stvar, da ukloni šut sa parcele), ili da ne uradi (da ne prolazi preko parcele, da ne parkira auto na njoj, da ne proizvodi imisije). ${ }^{46}$ To je upravo posledica savremenog učenja o subjektivnim pravima. Rečeno uopšte nije uslovljeno stavom da je državina kao takva subjektivno pravo. Jer, čak i da se to ne-

${ }^{43}$ Up. A. Jakšić, 65 i dalje (br. 89 i dalje); B. Poznić, V. Rakić-Vodinelić, 67 i dalje; za austrijsku doktrinu upor. W. Rechberger, D.-A. Simotta, 7-8 (br. 18 i dalje).

${ }^{44}$ Za takav argument vid. BVerfG (nemački Savezni ustavni sud), 12.2.1992 - 1 BvL 1/89 Neue Juristische Wochenschrift 1992, 1673; L. Rosenberg, K.-H. Schwab, P. Gottwald, 15 (§ 3 br. 4).

${ }^{45}$ Upor. H. Koziol, R. Welser, 44/45; Georg Kodek, u: A. Fenyves, F. Kerschner, A. Vonklich (Hrsg.), ABGB Klang, Bd. 6A, Wien 201133, 554 (§ 366 br. 1): ,radi se o zahtevu izvedenom iz stvarnog prava, otuda o stvarnopravnom zahtevu".

${ }^{46}$ Vid. već Lazar Marković, Građansko pravo, prva knjiga, Opšti deo i Stvarno pravo, Beograd 1912, 282; izričito danas V. Vodinelić (2012), 211, 238; upor. V. Vodinelić (2015), 35; u hrvatskoj teoriji Nikola Gavella, u: N. Gavella et alt., Stvarno pravo, Zagreb 2007², 234. 
gira, što je većinski slučaj, opet je državinski zahtev subjektivno pravo. ${ }^{47}$ Kako je rečeno, nastanak zahteva uopšte ni ne pretpostavlja povredu postojećeg subjektivnog prava.

\subsection{Rokovi trajanja državinskih zahteva umesto roka za tužbu}

Iz pojma državinskog zahteva proizlazi pravi smisao roka za sudsku zaštitu iz čl. 77 ZOSPO, što je samo razrada opšte koncepcije. Naime, ukoliko je utuženje jednog prava oročeno, to nije ništa drugo do propisivanje ograničenog vremenskog trajanja jednog prava. U rezultatu, državinski zahtev kao subjektivno pravo se gasi istekom predviđenih rokova, isto kao što se pravo traženja poništaja ugovora, kao pravo preobražajne tužbe, gasi istekom rokova iz čl. 117 ZOO.

Ovaj stav je razumljiv ukoliko se pođe od razlikovanja zastarelosti i prekluzije. Kao što je već rečeno, još uvek većinsko akcionopravno shvatanje polazi od toga da se zastarelošću ne gubi samo pravo, već zahtev, tj. tužba u materijalnom smislu, a kod prekluzije dolazi do gubitka prava. Suprotno, savremeno učenje o zahtevu drugačije objašnjava zastarelost, time i prekluziju. Zastarelost u smislu proteka potrebnog vremena, pre svega, sama za sebe ne znači ništa u odnosu na zahtev, već se time stvara tek protivpravo pasivne strane - nastanak prava prigovora, prava da odbije ispunjenje zahteva (Leistungsverweigerungsrecht). ${ }^{48} \mathrm{Tek}$ ukoliko se ovo, takođe subjektivno pravo ${ }^{49}$ ostvari izjavom volje - isticanjem prigovora $^{50}$ - dolazi do promene, koja se manifestuje u trajnoj suspenziji sudske

${ }^{47}$ Upravo tako, primera radi, Manfred Wolf, Sachenrecht, München 2006²2, br. 165: ,[i]ako državina kao faktička vlast na stvari sama nije subjektivno pravo, iz nje proizlaze subjektivna prava odbrane [državinski zahtevi, prim. aut.] [...]”.

${ }^{48}$ Upor. već za domaću doktrinu L. Marković (1912), 264; Srećko Zuglia, Prirodne obaveze u teoriji i srpskom privatnom pravu, Subotica 1924, 8. Učenje o prigovornoj prirodi zastarelosti se vraća na učenje Vindšajda, vid. B. Windscheid, 321. Kasnije je ono uobičeno u prigovorno pravo pasivne strane da odbije ispunjenje obaveze, kako je to na kraju uobličeno u nemačkom Građanskom zakoniku. Ovu koncepciju prihvata deo savremene austrijske doktrina, i pored toga što se u austrijskom Opštem građanskom zakoniku tako nešto ne spominje; tako izričito Peter Vollmaier, u: A. Fenyves, F. Kerschner, A. Vonklich (Hrsg.), ABGB Klang, Bd. 26, Wien 20123 , 39-40 sa daljim upućivanjima (§ 1451 br. 8).

${ }^{49}$ Da se radi o subjektivnom pravu nesporno je u nemačkoj doktrini, ali ne postoji saglasnost koje je prirode; up. H. Brox, 289 (br. 611), koji prosto govori o subjektivnom pravu; D. Medicus, 41 (br. 86) koji ga svrstava u preobražajna prava; H. Köhler, 231 (§ 17 br. 13) koji ga svrstava u relativna prava. I u domaćoj doktrini, ali manjinski, postoji stav da se radi o subjektivnom pravu; vid. već Lazar Marković, Građansko pravo, Beograd 1927², 87: „subjektivno pravo”; M. Knežević (2014), 343: , preobražajno pravo”.

${ }^{50}$ Up. R. Bork, 133 (br. 315); Marko Knežević, Raspravno načelo u srpskom parničnom postupku, Beograd 2016, 422 i sled.; M. Knežević (2014), 343 i sled. 
ostvarivosti zahteva: on je lišen tog svojstva, ali opstaje. ${ }^{51}$ Prekluzija, s druge strane, znači gubitak zahteva kao takvog. Dakle, ne gubi se mogućnost zaštite, ${ }^{52}$ jer je to upravo ono što se gubi isticanjem prigovora zastarelosti. Jednostavno, prekluzijom zahtev prestaje da postoji, gasi se, isto kao u slučaju drugih načina njegovog gašenja: ako protekne rok, zahtev je prestao, jednako kao da je on ispunjen, ili je ispunjenje nemoguće. To što je u najvećem broju slučajeva zakonska redakcija takva da se govori o roku za sudsku zaštitu, ili roku za tužbu, kako je rečno, samo je relikt akcionopravnog učenja, i ne menja rečeno. Isto tako, prekluziji nisu podložna samo preobražajna prava kako se to ponekad tvrdi, ${ }^{53}$ već i sva druga, uključujući i zahteve. ${ }^{54}$ Štaviše, trend je u domaćem pravu da se sve više uvode prekluzivni rokovi za zahteve. ${ }^{55}$ Koliko je to pravnopolitčki opravdano, budući da je zahteve, a naročito potraživanja u okviru njih, primerenije podvrgunti režimu zastarelosti, drugo je pitanje.

\subsection{Međuishod: materijalnopravna priroda roka iz čl. 77 ZOSPO}

Okolnost da su rokovi za sudsku zaštitu državine zapravo rokovi postojanja državinskih zahteva kao subjektivnih prava, znači i da su oni materijalnopravne prirode. Ne odnose se na postupak, nisu rokovi za vršenje parničnih radnji, odnosno od njih ne zavisi nastupanje procesnopravnih dejstva. Oni se odnose na sâmo postojanje prava koje je nesumnjivo materijalnopravne prirode, isto kao i drugi rokovi iste kategorije, poput roka trajanja autorskog prava. Radi se, dakle, o čistom materijalnopravnom dejstvu.

${ }^{51}$ V. Vodinelić (2012), 212, 521; N. Gavella, (2013), 198 fn. 31; M. Knežević (2014), 343 i sled.; za nemačku doktrinu umesto svih R. Bork, 133 (br. 314;) za zastupljenost ovog shvatanja u austrijskom pravu umesto svih Peter Vollmaier, u: A. Fenyves, F. Kerschner, A. Vonklich (Hrsg.), $A B G B$ Klang, $B d$. 26, Wien $2012^{3}$, 39-40 sa daljim upućivanjima ( $\$ 1451$ br. 8).

52 Tako međutim za prekluziju, iako difuzno, I. Babić, 242 (br. 990).

53 Tako Obren Stanković, u: O. Stanković, V. Vodinelić, Uvod u građansko pravo, Beograd $2007^{5}$, 213. Upor. D. Medicus, 47-48 (br. 100-101) koji polazi od takve teze, ali priznaje da nju nije moguće dosledno održati zbog pozitivnopravnih primera prekuzivnih rokova za neke zahteve.

${ }^{54}$ Up. V. Vodinelić (2012), 526/527.

${ }^{55} \mathrm{U}$ Zakonu o privrednim društvima je za brojna potraživanja predviđen prekluzivni rok (npr. čl. 18 st. 3, 28 st. 4, 197 st. 2). Dalje, u većini zakona koji uređuju pravo intelektualne svojine su predviđeni prekuzivni rokovi za zahteve koji nastaju povredom ovih prava, a povrh toga i za odštetne zahteve, tj. potraživanja (čl. 137 st. 1 Zakona o patentima; čl. 74 Zakona o oznakama geografskog porekla; čl. 65 st. 1 Zakona o pravnoj zaštiti industrijskog dizajna; čl. 74 st. 1 Zakona o žigovima). 


\subsection{Dogmatička opravdanost svrstavanja blagovremenosti tužbe u procesne pretpostavke}

Priroda rokova za utuženje bilo kog prava, pa i državinskih zahteva, morala bi da ima posledice na način odlučivanja u postupku kada je istekao rok, tj. kada je tužba neblagovremena. Sud bi morao meritorno da odluči, i to negativno - da odbije tužbeni zahtev. Međutim, kako je rečeno, u domaćem pravu odavno izričito važi drugačiji režim, po kojem je pitanje blagovremenosti tužbe procesna pretpostavka; ako je tužba neblagovremena, ona se odbacuje. Zapravo, iz koncepta procesnih pretpostavki - uslovi koji moraju da postoje da bi se uopšte meritorno raspravljalo, potom i meritorno odlučivalo - proizlazi da o neblagovremenoj tužbi uopšte ne sme da se meritorno odluči, pa čak i da tuženi prizna tužbeni zahtev. Jer, i da bi se donela takva presuda (odnosno rešenje u posesornom sporu), procesne pretpostavke moraju da budu ispunjene.

Potez zakonodavca, kao što je rečeno, kritikovan je u procesnoj literaturi, upravo argumetima koji su ovde izneti: radi se o pitanju koje je materijalnopravnog karaktera. ${ }^{56}$ Međutim, postoji i stavovi koji opravdavaju postojeći koncept. U tom smislu, Dika zastupa stav da istek roka za tužbu zapravo znači prestanak ,judicijabilosti određenog slučaja”, te prestanak nadležnosti domaćeg suda za njegovo rešavanje, konačno nedopuštenost sudskog puta pravne zaštite, te je u tom smislu odbacivanje tužbe opravdano. ${ }^{57} \mathrm{~S}$ druge strane, Jakšić smatra da je neblagovremenost tužbe pojavni oblik neutuživosti, koja je procesna smetnja. ${ }^{58}$

Stav Dike ne treba shvatiti tako da on tvrdi da protekom rokova za tužbu prestaje međunarodna nadležnost domaćeg suda (iako je postojala), odnosno da prestaje nadležnost suda kao državnog organa, tako da je sada nadležan neki drugi organ. Suštinski gledano, stav se vraća na jednu teorijsku varijantu tuživosti subjektivnog prava: ako je protekao rok za tužbu - rok za obraćanje sudu - onda je isključeno meritorno bavljenje suda, tj. tužba čija osnovanost zavisi od jednog takvog prava je nedozvoljena. ${ }^{59}$ Međutim, Dika na drugom mestu sasvim drugačije shvata tuživost, tako da ona nije procesna pretpostavka, već kvalitet samog subjektivnog prava; kraće: to je pitanje merituma. ${ }^{60}$

${ }^{56}$ Vid. gore fn. 22.

${ }^{57}$ M. Dika (2008), 66 fn. 87.

${ }^{58}$ A. Jakšić, 422 (br. 2094).

59 Tako za samo pojedine, izolovane slučajeve u nemačkom pravu, kada se rok za tužbu kvalifikuje kao isključenje tuživosti; upor. sa daljim upućivanjima Urlich Foerste, u: J. Musielak (Hrsg.), Kommentar zur Zivilprozessordnung, München 2013ํ, 886 (ispred $§ 253$ br. 6); L. Rosenberg, K.-H. Schwab, P. Gottwald, 489-491 (§ 89 br. 23, 29).

${ }^{60}$ Mihalo Dika, Građansko parnično pravo, Tužba, VI. knjiga, Zagreb 2009, 26 i sled. 
Jakšić s druge strane zastupa šire shvatanje tuživosti: to je bilo koje isključenje podobnosti jednog subjektivnog prava da bude predmet zaštite. Pored neblagovremene tužbe, to je za njega i zahtev iz privatne opklade, te i tada tužbu treba odbaciti. ${ }^{61}$ Ipak, upravo taj primer je i u nemačkom, i u austrijskom pravu, primer utuživosti kao materijalnopravne kategorije, što u rezultatu znači da se tužba odbija. ${ }^{62}$ Radi se o nepotpunim, nesavršenim potraživanjima (unvollkommene/unvollständige Forderungen) koje počivaju na pravnom poslu koji ne stvara obaveznost, ali ukoliko se one ispune, nema kondikcijskog zahteva. ${ }^{63}$ Dakle, to je primer za prirodne obaveze u našem pravu (čl. 213 ZOO). Nedostatak tuživosti je tu zaista stvar materijalnopravne komponente, pa je zato ispravan stav da tužbu treba odbiti.

Kada se rečeno prenese na polje rokova za tužbu, a imajući u vidu njihovu dogmatičku prirodu, čini se da se ne može govoriti o njima u kontekstu tuživosti. Zakonska redakcija odredaba koje oročavaju tužbu, kako je rečeno, ima prirodu oročavanja samog subjektivnog prava, a ne svesnu odluku zakonodavca da isključi pozivanje suda i u tom smislu sudsku zaštitu. ${ }^{64}$ Stoga, ukoliko se podnese neblagovremena tužba, onda ona nije nedozvoljena zbog toga što je utuženo pravo prestalo; ona je neosnovana upravo zbog toga. No, sve dok se ZPP ne izmeni u tom pravcu, dogmatički nesklad ostaje. Takve greške zakonodavca mogu da se saniraju isključivo kroz zakonodavne promene.

${ }^{61}$ A. Jakšić, $422-423$ (br. 2095 i dalje).

${ }^{62}$ Za nemačko pravo: BGH, 4.3.2004 - III ZR 124/03, NJW Rechtsprechungs-Report 2004, 778 sa daljim upućivanjima; U. Foerste, u: J. Musielak (Hrsg.), 886 (ispred $\S 253$ br. 6); L. Rosenberg, K.-H. Schwab, P. Gottwald, 489 (§ 89 br. 22); Reinhold Greger, u: Zöller, Zivilprozessordnung, Köln $2007^{26}, 791$ (ispred $\S 253$ br. 19). Za austrijsko pravo: W. Rechberger, D.-A. Simotta, 257 sa daljim upućivanjem i na suprotne stavove (br. 507); Martin Stefula, u: A. Fenyves, F. Kerschner, A. Vonklich (Hrsg.), ABGB Klang, Bd. 23, Wien 2012³ , 77-78 ( $§ 1270-1272$ br. 70). Upor. i OGH, 18.3.1976 - 7 Ob 255/75, Entscheidungen des österreichischen Obersten Gerichtshofes in Zivilsachen (SZ) 49, br. odluke 40 za generalni stav da je tuživost u austrijskom pravu pitanje materijalnog prava.

${ }^{63}$ Iz nemačke perspektive umesto svih Dieter Medicus, Schuldrecht I, Allgemeiner Teil, München 200617, 9-10 (br. 24); vid. \$§ 656, 762 nemačkog Građanskog zakonika.

${ }^{64} \mathrm{Kada}$ je to po sredi onda se radi o neutuživosti kao procesnoj smetnji, koja je po svojoj prirodi ista isključivanju redovnog pravnog puta; tako austrijska doktrina: Hans Fasching, u: H. Fasching (Hrsg.), Kommentar zu den Zivilprozeßgesetzen I, Wien 2000², Einl. br. 153 sa daljim upućivanjem; W. Rechberger, D.-A. Simotta, 257-258 (br. 507). Za shvatanje nemačke doktrine i sudske prakse up. samo L. Rosenberg, K.-H. Schwab, P. Gottwald, 489-491 (§ 89 br. 23, 29). 


\section{LITERATURA I IZVORI}

Attila Fenyves, Ferdinand Kerschner, Andreas Vonklich (Hrsg.), ABGB Klang, Bd. 6, Wien $2011^{3}$

Attila Fenyves, Ferdinand Kerschner, Andreas Vonklich (Hrsg.), ABGB Klang, Bd. 6 , Wien $2011^{3}$

Attila Fenyves, Ferdinand Kerschner, Andreas Vonklich (Hrsg.), ABGB Klang, Bd. 23, Wien $2012^{3}$

A. Fenyves, F. Kerschner, A. Vonklich (Hrsg.), ABGB Klang, Bd. 26, Wien $2012^{3}$

Bernhard Windscheid, Lehrbuch des Pandektenrechts I, Düsseldorf $1875^{4}$

Carl Friedrich von Savigny, System des heutigen römischen Rechts, Bd. V, Berlin 1841

Dieter Medicus, Allgemeiner Teil des BGB, Heidelberg $2002^{8}$

Dieter Medicus, Schuldrecht I, Allgemeiner Teil, München $2006^{17}$

Hans Brox, Allgemeiner Teil des BGB, München $1999^{23}$

Hans Fasching (Hrsg.), Kommentar zu den Zivilprozeßgesetzen I, Wien $2000^{2}$

Hans Fasching, Andreas Konecny (Hrsg.), Kommentar zu Zivilprozessgesetzen, Bd. III/1, Wien $2017^{3}$

Hans Fasching, Lehrbuch des österreichischen Zivilprozeßrechts, Wien $1990^{2}$

Hans Prütting, Gerhard Wegen, Gerd Weinreich (Hrsg.), BGB Kommentar, Köln $2009^{4}$ Harry Westermann, Sachenrecht, Karlsruhe $1960^{4}$

Helmut Köhler, BGB Allgemeiner Teil, München $2007^{31}$

Helmut Koziol, Rudolf Welser, Grundriss des bürgerliches Rechts, Bd. I, Wien $2000^{11}$

Jaochim Musielak (Hrsg.), Kommentar zur Zivilprozessordnung, München $2013^{10}$

Karl-Heinz Schwab, Sachenrecht, München $1989^{22}$

Leo Rosenberg, Karl-Heinz Schwab, Peter Gottwald, Zivilprozessrecht, München $2010^{17}$

Ludwig Raiser, „Der Stand der Lehre vom subjektiven Recht im Deutschen Zivilrecht", Juristenzeitung 1961, 465

Nikola Gavella et alt., Stvarno pravo, Zagreb 2007², 234

Nikola Gavella, „O odnosu materijalnog i procesnog građanskog prava u parnicama”, u: A. Uzelac, J. Garašić, A. Maganić (ur.), Djelotvorna pravna zaštita u pravčnom postupku, Liber amicorum Mihajlo Dika, Zagreb 2013

Oskar Ballon, Einführung in das österreichischen Zivilprozessrecht, Graz $2009^{12}$

Reinhard Bork, Allgemeiner Teil des Bürgerliches Gesetzbuchs, Tübingen 2011 ${ }^{3}$

Srećko Zuglia, Ante Verona, Zakonik o sudskom postupku u građanskim parnicama (Građanski parnični postupak) (s.a.)

Stein/Jonas, Kommentar zur Zivilprozessordung, Bd. IV, Tübingen $2008^{22}$

W. Rechberger, T. Klicka (Hrsg.), Kommentar zur ZPO, Wien $2019^{5}$

Walter Rechberger, Daphne-Ariane Simotta, Zivilprozessrecht, Wien $2009^{7}$

Wieczorek/Schütze, Zivilprozessordnung und Nebengesetze, Bd. 4, Berlin $2013^{4}$

Zöller, Zivilprozessordnung, Köln $2007^{26}$

Aleksandar Jakšić, Građansko procesno pravo, Beograd 20179,

Andrija Gams, Ljiljana Đurović, Uvod u građansko pravo $1994^{17}$

Borivoj Starović, Ranko Keča, Građansko procesno pravo, Novi Sad $2004^{3}$ 
Borivoje Poznić, Vesna Rakić-Vodinelić, Građansko procesno pravo, Beograd $2015^{17}$ Borivoje Poznić, Građansko procesno pravo, Beograd 1962

Borivoje Poznić, Komentar Zakona o parničnom postupku, prema tekstu zakona iz 1976. godine sa docnijim izmenama i dopunama, Beograd 2009

Borivoje Poznić, Mihailo Vražalić, Franjo Bačić, Zakon o parničnom postupku, sa komentarom, Beograd 1957

Vladimir Vodinelić, Građansko pravo, Uvod u građansko pravo i Opšti deo građanskog prava, Beograd 2012

Vladimir Vodinelić, Državina, Beograd 2015

Gordana Stanković, Građansko procesno pravo, Niš $2007^{7}$

Danica Popov, Građansko pravo, Novi Sad 2012

Danica Popov, „Tužba zbog smetanja državine izazvanih imisijama”, Zbornik Pravnog fakulteta u Novom Sadu 2015, 1498

Dejan Đurđević, Institucije naslednog prava, Beograd $2015^{7}$

Dragoljub Aranđelović, Građansko procesno pravo Kraljevine Jugoslavije II, Beograd 1933

Dušan Nikolić, Uvod u sistem građanskog prava, Novi Sad $2013^{11}$

Ilija Babić, Građansko pravo, Knjiga 1, Uvod u građansko pravo, Beograd 2011

Lazar Marković, Građansko pravo, Beograd $1927^{2}$

Lazar Marković, Građansko pravo, prva knjiga, Opšti deo i Stvarno pravo, Beograd 1912

Marko Knežević, „Krug opozicionih razloga u prigovoru protiv rešenja o izvršenju na osnovu izvršne isprave“, Zbornik radova Pravnog fakulteta u Novom Sadu $4 / 2014$

Marko Knežević, „Teret dokazivanja imisija kao pretpostavke negatornog zahteva“, Zbornik radova Pravnog fakulteta u Novom Sadu 4/2013

Marko Knežević, Raspravno načelo u srpskom parničnom postupku, Beograd 2016

Milijan Popović, Pojam subjektivnog prava, Novi Sad 1974

Milka Janković et alt., Komentar Zakona o parničnom postupku, Beograd $1990^{3}$

Milka Janković et alt., Komentar Zakona o parničnom postupku, Beograd 1977

Miroslav Lazić, „Pravna dejstva državine prema Srpskom građanskom zakoniku”, u: Zbornik radova Pravnog fakulteta u Nišu 'Sto pedeset godina od donošenja Srpskog građanskog zakonika (1844-1994)“, Niš 1995

Mihajlo Dika, Pravo na tužbu, Zagreb 1987

Mihalo Dika, Građansko parnično pravo, Parnične radnje, V. knjiga, Zagreb 2008

Mihalo Dika, Građansko parnično pravo, Tužba, VI. knjiga, Zagreb 2009

Obren Stanković, Vladimir Vodinelić, Uvod u građansko pravo, Beograd $2007^{5}$

Obren Stanković, Miodrag Orlić, Stvarno pravo, Beograd $1995^{9}$

Radmila Kovačević Kuštrimović, Miroslav Lazić, Stvarno pravo, Niš 2006

Radmila Kovačević Kuštrimović, Miroslav Lazić, Uvod u građansko pravo, Niš 2008

Siniša Triva, Velimir Belajec, Mihajlo Dika, Građansko parnično procesno pravo, Zagreb $1986^{6}$

Siniša Triva, Građansko procesno pravo I, Zagreb $1972^{2}$ 
Slavica Krneta, „Evolucija pojma ,zahtjev“ i njegov odnos prema subjektivnom pravu“, Godišnjak Pravnog fakulteta u Sarajevu XXIII (1975)

Slavica Krneta, „Posjed”, u: Enciklopedija imovinskog prava i prava udruženog rada, Beograd 1978

Slavica Krneta, „Subjektivna prava“, u: Enciklopedija imovinskog prava i prava udruženog rada, Beograd 1977

Srećko Zuglia, Prirodne obaveze u teoriji i srpskom privatnom pravu, Subotica 1924

Srećko Culja, Građansko procesno pravo Kraljevine Jugoslavije, sv. 1, Beograd 1936

Franjo Goršić, Komentar Građanskog parničnog postupka II, Beograd 1932 
Dr. Marko S. Knežević, Dozent

Universität Novi Sad

Juristische Fakultät

mknezevic@pf.uns.ac.rs

Dr. Radenka M. Cvetić, ordentliche Professorin

Universität Novi Sad

Juristische Fakultät

rcvetic@pf.uns.ac.rs

\section{Die Natur der Fristen zum gerichltichen Besitzschutz (Art. 77 EigentumsG)}

Zusammenfassung: Gerichtlicher Besitzschutz-sog. posessorischer Schutz, der in der besonderen Verfahrensart gewährleistet wird - ist befristet (Art. 77 Gesetz über Eigentumsrechtlichegrundrisse-EigentumsG). Die h.M. spricht dabei von die Fristen der sog. Besitzklagen, die ihrer Natur nach materiellrechtlich sind. Zudem aber behandelt sie der Gesetzgeber nach wie vor z.T. als prozessual, weil eine unrechtzeitige Klage zurückzuweisen ist. Ausgegangen von einer im Vergleich mit noch überwiegender heimlichen Lehre verschiedene Auffassung der subjektiven Rechten wird im Aufsatz die Rechtsnatur dieser Fristen aufgegriffen. Aus der Besitzstörung hervorgehen die possesorische Ansprüche als besondere Art der subjektiven Rechten, dagegen kein bloßes Klagerecht. Die Fristen aus Art. 77 Eigentums $G$ sind nichts anders als die Zeit, in der ein Anspruch besteht. Daher sind sie präklusiv und materiellrechtlich.

Schlüsselwörter: gerichtlicher Besitzschutz; Klagefirst; subjektives Recht; Anspruch.

Datum prijema rada: 08.11.2019. 